\title{
LA GRABACIÓN COMO TEXTO, EL PRODUCTOR COMO EDITOR Y EL COMPOSITOR COMO INTÉRPRETE: JOHN CULSHAW Y BENJAMIN BRITTEN (1963-1970) ${ }^{1}$
}

\author{
Pablo-L. Rodríguez \\ Universidad de La Rioja
}

RESUMEN: Al escuchar una grabación de música clásica no solemos reparar en la labor del productor y nos limitamos a considerar tan sólo al compositor y al intérprete. Sin embargo, la importancia e influencia de los productores ha sido determinante durante toda la historia de la grabación musical; su labor evolucionó a lo largo del segundo tercio del siglo XX desde la concepción de la grabación como fotografía de una interpretación en los años treinta hasta su consideración como objeto artístico en los sesenta, pasando por la visión idealista del concierto en los cuarenta y cincuenta. Uno de los productores más importantes y novedosos de los años cincuenta y sesenta fue John Culshaw (1924-1980) que consideró la grabación como otro texto, además de la partitura, a la hora de documentar la obra musical; un texto mucho más rico que los signos de notación al documentar una obra musical en su manifestación sonora. Culshaw diseñó todo un sistema de producción musical que puso en práctica en su mítica grabación del Anillo de Wagner entre 1958 y 1965 donde separó la grabación del planteamiento idealista del concierto en vivo o pretendió paliar la pérdida de lo visual a través de medios técnicos y acústicos conocidos como "Sonicstage". En este artículo me centraré en su colaboración con el compositor Benjamin Britten (19131976), de la que nacieron registros fonográficos clásicos para Decca (War Requiem en 1963) y audiovisuales para la BBC (Peter Grimes en 1969), en los que el compositor inglés dirigía sus obras y que le llevarían a escribir una ópera especialmente pensaba para su emisión televisiva (Owen Wingrave en 1970).

1. Este artículo se enmarca en el proyecto I+D HAR2011-22712. Me gustaría dedicarlo con cariño y admiración a Eduardo Benarroch y a Heather Harper en recuerdo de una maravillosa reunión para tomar el té en su casa el 1 de enero de 2007 junto a Anita Lasker-Wallfisch y en donde tantas cosas aprendí de primera mano sobre Benjamin Britten. 
Palabras clave: Grabación, productor, compositor, obra, edición, interpretación, filmación.

\title{
THE RECORDING AS TEXT, THE PRODUCER AS EDITOR AND THE PERFORMER AS INTERPRETER: JOHN CULSHAW AND BENJAMIN BRITTEN (1963-1970)
}

\begin{abstract}
When we listen to a recording of classical music often forget the influence of the producer and consider only the composer and the performer. However, the importance and influence of producers has been decisive throughout the history of recorded music; their labour evolved over the second third of the 20th century from conception of the recording as a photograph of a performance in the 1930s to the consideration as a work of art in the 1960s, through the idealistic view of the concert in the 1940s and 1950s. One of the most important and innovative producers of the 1950s and 1960s was John Culshaw (1924-1980). He saw the recording as other text in addition to the score, when documenting the musical work, a much richer text that documents a musical work in its sound manifestation. Culshaw designed an entire music production system implemented in his legendary recording of Wagner's Ring between 1958 and 1965 which separated the approach to the recording as idealistic concert or sought to exceed the loss of the visual through technical and acoustic media known as "Sonicstage". In this article I will focus on his collaboration with composer Benjamin Britten (1913-1976), with whom he recorded some classic discs for Decca (War Requiem in 1963) and videos for the BBC (Peter Grimes in 1969), in which the English composer directed his own works and that would take him to write an opera especially for broadcast by television (Owen Wingrave in 1970).
\end{abstract}

Keywords: Recording, producer, composer, work, editing, performance, filming.

Cuando escuchamos una grabación a menudo olvidamos que no percibimos tan sólo a un músico o un conjunto de ellos interpretando una obra concreta, sino también lo que un productor ha seleccionado de aquello que ha registrado un ingeniero de sonido en un soporte sonoro. Evidentemente, la influencia del productor y del ingeniero de sonido sobre el resultado artístico de una grabación ha evolucionado sustancialmente, aunque, a diferencia de la música popular, donde nunca ha habido ningún problema en considerar la influencia del productor o en reconocer su aportación (pensemos, por ejemplo, en Georges Martin, el conocido como "quinto Beatle") $)^{2}$, en la música clásica todo ha sido muy diferente y

2. George Martin y Jeremy Hornsby: All You Need Is Ears: The inside personal story of the genius who created the Beatles. New York: St. Martin's, 1979. 
muchos intérpretes se han sentido invadidos por la labor del equipo técnico de una grabación. Hay numerosas anécdotas sumamente ilustrativas sobre ello desde los inicios de la era eléctrica hacia mediados de los años veinte del siglo pasado en que se comenzó a registrar la música con micrófono, es decir, con la misma disposición y en las mismos lugares donde se celebraban las representaciones operísticas o los conciertos; por ejemplo, Alexander Kipnis en 1933 echó al equipo técnico durante una grabación de lieder de Hugo Wolf y reconoció que había hecho su mejor disco sin ingenieros ${ }^{3}$; o Wilhelm Furtwängler dedicó a Friedrich Schnapp, el ingeniero de la emisora del Reich durante la Segunda Guerra Mundial, un extraño halago: "Lo más maravilloso de usted es que no les hace absolutamente nada a sus retransmisiones" ${ }^{\prime 4}$. Obviamente Kipnis hizo su disco de Wolf con ingenieros y Schnapp manipulaba las retransmisiones de Furtwängler, pero ambas anécdotas reflejan precisamente ese rechazo de los músicos clásicos por la labor de productores e ingenieros de sonido.

Y ese rechazo no se circunscribe tan sólo a los músicos que participaban en las grabaciones, sino también a algunos críticos que en los años cincuenta y sesenta del siglo pasado atacaron duramente las grabaciones en general y la intervención de productores y técnicos de sonido en particular. Un ejemplo lo encontramos en Kurt Oppens, el histórico crítico y autor de notas al programa en el Aspen Music Festival desde 1957 a 1995, que en 1963 publicó en la revista intelectual Merkur un breve artículo donde atacaba tanto la pretensión como la corrupción de los registros sonoros: "Las grabaciones sonoras roban al oyente no sólo la posibilidad de ver la producción del sonido, sino que también falsifican la interpretación, especialmente por la interferencia que representan los ingenieros acústicos y musicales". Oppens afirma además que la posibilidad de repetir pequeñas secciones de una obra musical deshecha toda espontaneidad artística y hace que las grabaciones muestren mayor competencia que la del músico registrado; acusa también a las grabaciones de estar incluso determinando el diseño acústico de las nuevas salas de concierto del momento, algo que por entonces (en 1963) se pudo experimentar en la debacle acústica del nuevo Philharmonic Hall en el Lincoln Center de Nueva York ${ }^{5}$.

3. John Harvith y Susan E. Harvith: Edison, musicians and the phonograph: a century in retrospect. New York: Greenwodd Press, 1987, p. 93.

4. "Friedrich Schnapp (1900-1983)" en Wilhelm Furtwängler In Memoriam. CD-ROM: Tahra, FURT 1090-93, 2004. Su contenido se encuentra disponible en la web de la Société Wilhelm Furtwängler: http://www.furtwangler.net/inmemoriam/data/schna_en.htm.

5. "Die Schallplattenaufnahme beraubt der Hörer nicht nur des Visuellen der Tonerzeugung, sie verfälscht auch die Aufführung: Zwischeninstanzen schieben sich ein, akustische und musikalische Ingenieure". Cfr. Kurt Oppens: "Anspruch und Verführung der Schallplatte", Merkur, 188 (1963), p. 1012-1015 (1014-15). Sobre la debacle acústica del Philharmonic Hall neoyorquino véase J. Christopher Jaffe: The Acoustics of Performance Halls. Nueva York: W.W. Norton \& Company, 2010. 
Conviene recordar que la labor de los productores fonográficos está relacionada con las primeras compañías discográficas y la comercialización del sonido grabado. Al parecer surgieron en la primeras décadas del siglo XX de los llamados $A \& R$, el personal de artistas y repertorio de las primeras discográficas y, más concretamente, con el "jefe de grabación y buscador de artistas" de la Gramophone Company desde 1900 hasta 1939 (ya convertida en EMI) Fred Gaisberg (1873$1951)^{6}$. Este ingeniero de sonido de origen norteamericano, que había sido un talento frustrado del piano en su juventud, concebía la grabación como una "fotografía sonora" de la interpretación musical todo lo borrosa o detallada que los medios técnicos permitiesen. Ciertamente esta concepción fue superada tras la inclusión de medios eléctricos, el desarrollo de las posibilidades del micrófono o el advenimiento del sonido estéreo, aunque Gaisberg marcó algunas características fundamentales de los productores venideros como las decisiones artísticas (qué grabar, cuándo, con quién y cómo) o la capacidad psicológica para tratar con artistas en extremo sensibles o arrogantes cuyas inseguridades, vicios y delirios hacían peligrar las grabaciones y perder dinero a la compañía para la que trabajaba.

La edad de oro de la producción discográfica de música clásica está asociada a los productores británicos Walter Legge (1906-1979), que trabajó para EMI principalmente en los años cincuenta, y John Culshaw (1924-1980) que lo hizo para Decca desde finales de los cincuenta hasta finales de los sesenta. Legge y Culshaw representaron dos formas de utilizar las posibilidades técnico-estéticas de la grabación musical. Para Legge la grabación permitía alcanzar un ideal interpretativo que suponía escuchar al mejor solista o conjunto posible desde el mejor asiento de una sala con una acústica perfecta ${ }^{7}$. Por su parte, John Culshaw abogaba por una similar perfección artística, pero se separó del planteamiento idealista del concierto en vivo de Legge y pretendió paliar la pérdida de lo visual a través de medios técnicos y acústicos; concretamente, el advenimiento comercial del sonido estereofónico a finales de los cincuenta permitió a Culshaw desarrollar su proyecto estético de sonido grabado que se conoce bajo el nombre de "Sonicstage" (o "escenografía sonora") y que está relacionado con la mítica grabación del Anillo wagneriano que produjo para Decca entre 1958 y 1965 en la Sofiensaal de Viena bajo la dirección musical de Georg Solti ${ }^{8}$.

6. Timothy Day: Un siglo de música grabada. Escuchar la historia de la música. Madrid: Alianza Música, 200, pp. 47-48. Sobre Gaisberg véase su libro Music on Record. Londres: Robert Hale Limited, 1947 y también Jerrold N. Moore: Sound Revolutions. A Biography of Fred Gaisberg, Founding Father of Commercial Sound Recording. Londres: Sanctuary Publishing, 1999 ( $2^{\text {a }}$ ed.).

7. Elisabeth Schwarzkopf: On and Off the Record. A Memoir of Walter Legge. Londres: Faber and Faber, 1982.

8. John Culshaw: Ring Resounding. New York: Viking Press, 1967 (reedición en Londres: Pimlico, 2012). Véase además del mismo autor Putting the Record Straight: The Autobiography of John Culshaw. Londres: Viking Press, 1982. 


\section{Imagen 1. \\ La Sofiensaal de Viena durante la grabación de Götterdämmerung en 1964.}

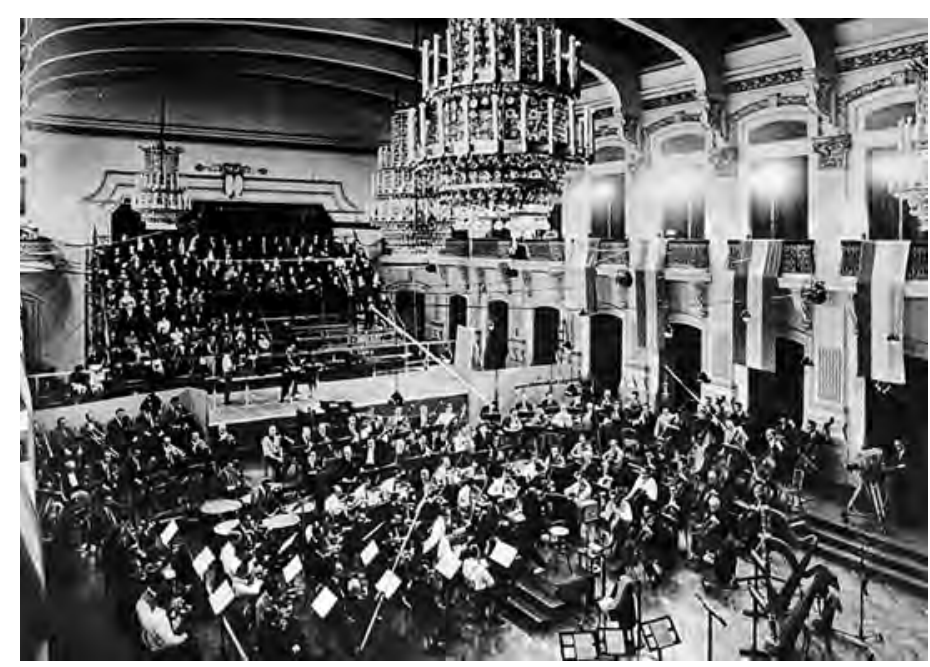

El Sonicstage promovido por Culshaw precisaba de una ubicación espacial similar a la habitual en un teatro de ópera (véase la imagen 1), pero también de todo un sistema de movimientos y efectos sonoros que enriquecían notablemente la grabación y aprovechaban todas las posibilidades que brindaba el sistema estereofónico. Ya en el registro del prólogo de la tetralogía wagneriana, Das Rheingold, grabado entre septiembre y octubre de 1958 en la Sofiensaal de Viena, encontramos los primeros ejemplos de efectos vinculados al Sonicstage; por ejemplo, en la tercera escena cuando el nibelungo Alberich se pone el Tarnhelm, el yelmo mágico que le hace invisible, y castiga a su hermano Mime sin que pueda verlo. Culshaw dispuso de una especie de cabina telefónica con su propio micrófono para cambiar el espectro sonoro y amplificar electrónicamente la voz del barítono Gustav Neidlinger, que cantaba el papel de Alberich, cuando se ponía el yelmo mágico; el productor británico defiende este efecto con la siguiente argumentación:

Todo esto no era más que una moderna extensión de lo que Wagner tenía en mente. La amplificación eléctrica no era conocida en la época del estreno de Das Rheingold, y por ello Wagner utilizó los únicos medios de los que disponía -una enorme bocina a través de la cual Alberich cantaba en los momentos que era invisible-. Como consecuencia de una errónea fidelidad a la tradición, muchos teatros todavía siguen usando esas bocinas o megáfonos tan ineficaces, pese a que un sencillo sistema con un micrófono fuera de escena conectado a varios altavoces distribuidos por la zona del escenario utilizada por Mime, y con una conmutación que permitiera que el sonido de la voz de Alberich pasara de 
un altavoz a otro según los movimientos de Mime, podría resolver con efectividad el problema? .

Como queda claro, Culshaw no pretendía contravenir las pretensiones del compositor, sino más bien todo lo contrario; en un documental filmado en 1964 por la BBC durante las sesiones de grabación del Götterdämmerung afirma que su máxima aspiración es "Hacer lo mejor por Wagner"10. En su afán por separar la idealista visión del concierto de la grabación como objeto, Culshaw convertirá a esta última en una obra de arte en sí misma, al conseguir traducir de una forma más perfecta cada partitura en un objeto sonoro y pretender convertirlo en el mejor documento posible de una obra musical. Para el productor británico la grabación va a ser otro texto, además de la partitura, a la hora de documentar la obra de arte musical; un texto mucho más rico que los signos de notación al documentar una obra musical en su manifestación sonora"1 .

Obviamente Culshaw no trabajaba solo sino que lideraba un equipo humano cuyo engranaje marcará un antes y un después en la historia de la producción fonográfica. En el referido documental de la BBC de 1964 realizado por Humphrey Burton pueden verse en acción lo que él denominó los "Decca Boys". Tal como podemos ver en un fotograma de ese documental (imagen 2), Culshaw se situaba en el centro con la partitura dirigiendo toda la parte técnica de la grabación, flanqueado a ambos lados por dos ingenieros de sonido: Gordon Parry al frente de los doce micrófonos de la orquesta y Jimmy Lock con los micrófonos de los cantantes y los efectos.

A ellos dos se unía Jack Law, que manejaba la máquina de grabación, y Christopher Raeburn a cargo de los movimientos de los cantantes del Sonicstage. El primero asistía al productor durante el montaje de la grabación y preparación del máster, es decir, el momento en que se editaba el resultado final y se aceptaba o descartaba cada toma sonora; esta labor la realizaba Culshaw fren-

9. "All this was only a modern extension of what Wagner himself had in mind. Electrical amplification was unknown at the time of the first performance of Rheingold, and so Wagner used the only means at his disposal-a vast speaking-tube through which Alberich was directed to sing during his invisible moments. Out of a misguided loyalty to tradition, many theatres still continue to use quite ineffective speaking-tubes and megaphones, although a very simple system of a single off-stage microphone linked to various speakers deployed around the stage area used by Mime, and with a switching facility to enable the sound of Alberich's voice to be moved from one speaker to another according to Mime's movements, would solve the problem effectively". Culshaw: Ring Resounding, op. cit., p. 104.

10. The Golden Ring - The Making of Solti's "Ring". DVD. Decca 0743196DH @2007.

11. Sobre la consideración de Culshaw de la grabación como una obra de arte, véase David Patmore \& Eric Clarke: "Making and hearing virtual worlds: John Culshaw and the art of record production", Musicae Scientiae 11 (2007), pp. 269-293 y David Patmore: "John Culshaw and the recording as a work of art", Journal of the Association of Recorded Sound Collections 39/1 (2008), pp. 20-40. 


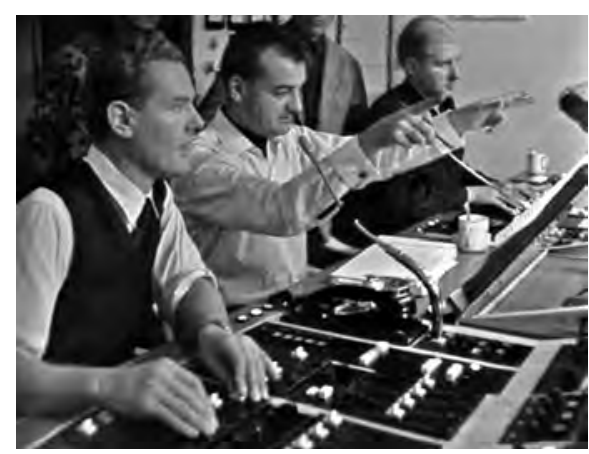

Imagen 2. Culshaw dirigiendo una sesión de grabación en la Sofiensaal en 1964.

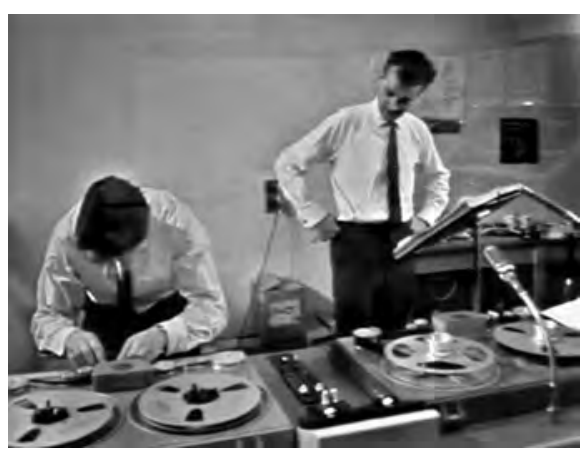

Imagen 3. Culshaw y Law durante una sesión de montaje en la Sofiensaal en 1964.

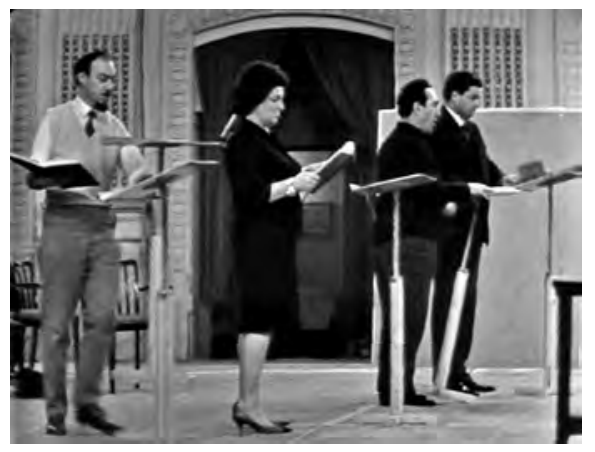

Imagen 4. Raeburn durante una sesión de grabación en la Sofiensaal en 1964.

te a la partitura con Law empalmando cada una de las tomas finales dentro de la cinta máster (imagen 3).

Por su parte, Raeburn asistía los movimientos de los cantantes durante la grabación, siguiendo un sistema de ubicación en el escenario similar al practicado en los teatros de ópera; arriba lo podemos ver asistiendo a Birgit Nilsson, Gottlob Frick y Dietrich Fischer-Dieskau durante la grabación de la escena final del segundo acto de Götterdämmerung (imagen 4)

Las ideas desarrolladas por Culshaw en su grabación del Anillo wagneriano serían determinantes en relación a las grabaciones que produjo de música contemporánea y, especialmente, de varias composiciones de Benjamin Britten. Aunque Culshaw y Britten se conocieron a comienzos de los cincuenta, tal y como reconoce el propio Culshaw en el obituario de Britten que publicó en Gramophone en 1977, no fue hasta los años sesenta cuando empezaron a tra- 
bajar de forma habitual ${ }^{12}$. En realidad, su primer registro juntos lo realizaron en 1953 y fue el concierto de apertura del Festival de Aldeburgh. Después trabajaron en algunos discos de canciones junto a Peter Pears; por ejemplo, en un Die schöne Müllerin de Schubert grabado entre 1958 y 1959; y en dos composiciones suyas donde el propio Britten actuó como director musical: la cantata The Little Sweep en 1955 y el ballet The Prince of the Pagodas en 1957. Su siguiente colaboración no se produjo hasta 1963, es decir, cuando ya Culshaw había desarrollado sus ideas sonoras acerca de la grabación en sus primeros registros de óperas de Strauss y del Anillo con Solti ${ }^{13}$.

Tabla 1. Grabaciones con Benjamin Britten como director o pianista producidas por Culshaw entre 1963 y 1970.

\begin{tabular}{|l|l|}
\hline AÑO & OBRAS GRABADAS \\
\hline 1963 & $\begin{array}{l}\text { Britten: War Requiem Op. 66 (audio Decca) } \\
\text { Obras de Bennett, Bridge e Ireland (audio Argo) } \\
\text { Schumann Dichterliebe Op. } 48 \text { (audio Decca) } \\
\text { Schubert Winterreise Op. 89 D911 (audio (Decca) } \\
\text { Britten: Cantata Misericordium Op. 69 (audio Decca) }\end{array}$ \\
\hline 1964 & $\begin{array}{l}\text { Britten: Albert Herring Op. 39 (audio Decca) } \\
\text { Britten: Cello Symphony Op. 68 (audio Decca) } \\
\text { Haydn: Cello Concerto No.1 in C H.VIllb.1 (audio Decca) } \\
\text { Tippett: Songs for Ariel (audio Argo) } \\
\text { Busch: Voices of the Prophets Op. 41 (audio Argo) } \\
\text { Obras de Busch, Delius, Grainger, Moeran, Warlock, etc (audio Argo) } \\
\text { Britten: Sinfonia da Requiem Op. 20 (audio Decca) }\end{array}$ \\
\hline 1965 & $\begin{array}{l}\text { Britten: Curlew River Op. 71 (audio Decca) } \\
\text { Britten: Songs and Proverbs of William Blake Op. 74 (audio Decca) }\end{array}$ \\
\hline 1966 & $\begin{array}{l}\text { Britten: Psalm 150 Op. 67 (audio Decca) } \\
\text { Britten: Friday Afternoons Op. 7/1-3 \& 5-12 (audio Decca) } \\
\text { Britten: A Midsummer Night's Dream Op. 64 (audio Decca) } \\
\text { Britten: Les Illuminations Op. 18 (audio Decca) }\end{array}$ \\
\hline 1967 & $\begin{array}{l}\text { Britten: The Burning Fiery Furnace Op. 77 (audio Decca) } \\
\text { Britten: Billy Budd Op. 50 (audio Decca) }\end{array}$ \\
\hline 1969 & Britten: Peter Grimes Op. 33 (video BBC) \\
\hline 1970 & $\begin{array}{l}\text { Schubert: Winterreise Op. 89 D911 (video BBC) } \\
\text { Britten: Owen Wingrave Op. 85 (video BBC) }\end{array}$ \\
\hline
\end{tabular}

12. John Culshaw: "Ben: A tribute to Benjamin Britten" en Gramophone (February, 1977), pp. 1251-1252.

13. Philip Stuart: Decca Classical Discography, 1929-2009. Londres: CHARM, 2009 http://www.charm.rhul.ac.uk/discography/decca.html. 
En la tabla 1 puede verse la asidua colaboración que mantuvo Culshaw con Britten entre 1963 y 1970. En ella destaca, en primer lugar, la grabación del War Requiem en 1963, que contó con el reparto vocal ideado por el compositor que incluía a Galina Vishnevskaya, Peter Pears y Dietrich Fischer-Dieskau, y después otras grabaciones orquestales como la Cello Symphony con Mstislav Rostropovich o el registro de una nueva ópera cada año: Albert Herring en 1964, Curlew River en 1965, A Midsummer Night's Dream en 1966 y Billy Budd en 1967. Después de que Culshaw dejara Decca en 1967, y pasará a ponerse al frente de la división musical de la BBC, ambos seguirían colaborando en varias filmaciones para la televisión tanto de Peter Grimes en 1969, como de Winterreise de Schubert en 1970 o la ópera televisiva Owen Wingrave ${ }^{14}$.

Me voy a centrar en ambos extremos de la colaboración entre Culshaw y Britten para mostrar la influencia que ejerció el productor en la reconsideración del War Requiem y en la concepción de Owen Wingrave.

Culshaw explica con gran precisión en su autobiografía póstuma e inconclusa todos los detalles acerca de su concepción del War Requiem o también sobre la planificación y el diseñó de la grabación que produjo en $1963^{15}$. Como es bien sabido, la obra fue encargada a Britten para la reapertura de la catedral de Coventry después de su destrucción durante la Segunda Guerra Mundial y combina el texto en latín de la misa de réquiem cantado por una soprano solista, coro y orquesta, pero también con participaciones de un coro de niños con órgano, con varios poemas antibélicos del soldado inglés Wilfred Owen, que son cantados por un tenor y un barítono acompañados por una pequeña agrupación instrumental. Britten había pensado la música para unos intérpretes concretos, tal como solía ser habitual en él, y además en este caso ese diseño de voces tenía la voluntad de unir a tres países que habían estado en guerra: una soprano rusa (Galina Vishnevskaya) un tenor inglés (Peter Pears) y un barítono alemán (Dietrich Fischer-Dieskau). Britten enseñó los primeros manuscritos de la obra a Culshaw y el productor británico se propuso iniciar las negociaciones con Decca para grabarla incluso antes de estar concluida; se trataba de un registro que planteaba numerosos problemas tanto de aceptación por parte de la compañía discográfica como también artísticos ante la complejidad de negociar los contratos con los cantantes elegidos por el compositor: Fischer-Dieskau era artista exclusivo del sello EMI y Vishnevskaya no obtuvo permiso de las autoridades soviéticas ni siquiera para viajar a Inglaterra para el estreno de la obra; tuvo que ser sustituida por la soprano británica Heather Harper. Por otro lado, la inmensidad del conjunto hizo que Britten renunciase a dirigir a todos los músicos y se limitó a conducir a la pequeña agrupación instrumental con

14. Ib.

15. Culshaw: Putting the Record Straight, op. cit., pp. 287-317. 


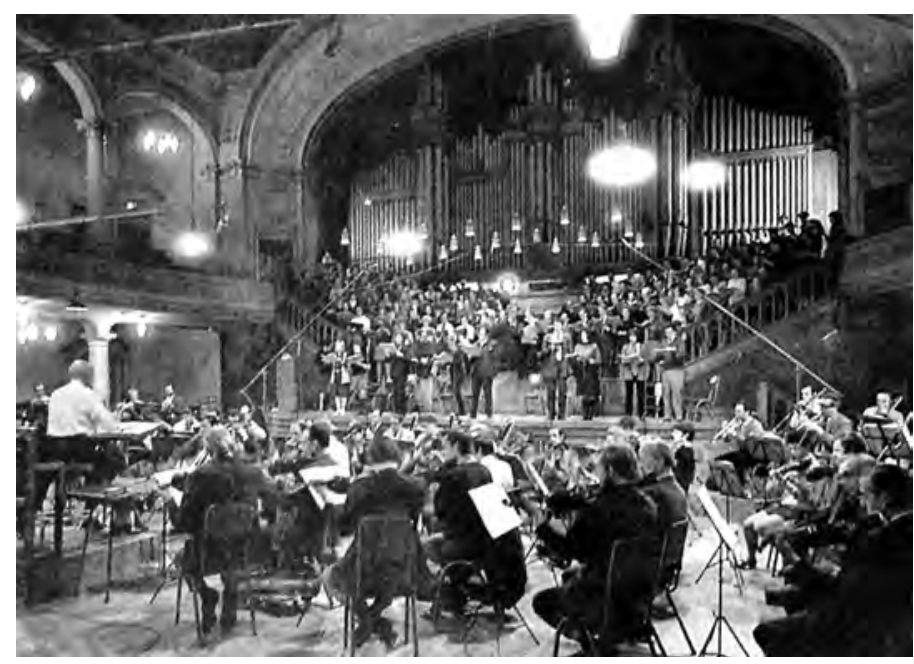

Imagen 5. Sir Adrian Boult grabando en 1970 con la London Philharmonic en el Kingsway Hall.

los dos cantantes solistas en las intervenciones con versos de Owen; el resto de la orquesta y voces fueron dirigidos por el joven Meredith Davies.

Inicialmente una posibilidad para llevar el War Requiem al disco con el menor coste posible era realizar una grabación en vivo aprovechando su estreno en la referida catedral de Coventry el 30 de mayo de 1962 con la City of Birmimgham Symphony Orchestra ${ }^{16}$. Esa propuesta de Decca fue desestimada por el propio productor haciendo valer su concepción artística y aduciendo que su propuesta no consistía simplemente en un "souvenir sonoro" para ser vendido con una miniatura de plástico de la catedral reconstruida. En realidad, Culshaw no había podido estar presente en el estreno, pues estaba grabando Siegfried en Viena, y tuvo que conformarse con escuchar la grabación realizada por la BBC. No obstante, ya entonces se percató de algunos graves problemas de conjunto que se propuso solventar cuando por fin obtuvo el plácet de Decca para grabar la obra; las negociaciones fueron difíciles pero consiguió reunir a los tres solistas en Londres en las dos primeras semanas de enero de 1963, dispuso de la Melos Ensemble, la London Symphony Orchestra con su coro, convenció a Britten para que dirigiera todo el conjunto y además utilizó la mejor sala de grabación de la capital británica: el Kingsway Hall, sede de la Iglesia metodista británica de planta circular con escenario y gran órgano (véase imagen 5) que se convirtió desde 1926 en una de las principales salas de grabación de Lon-

16. La grabación del estreno acaba de publicarse oficialmente; véase Benjamin Britten: War Requiem, Op. 66. World premiere performance recorded in Coventry Cathedral, May 1962 (2CDs). Testament SBT 1490 C2013. 

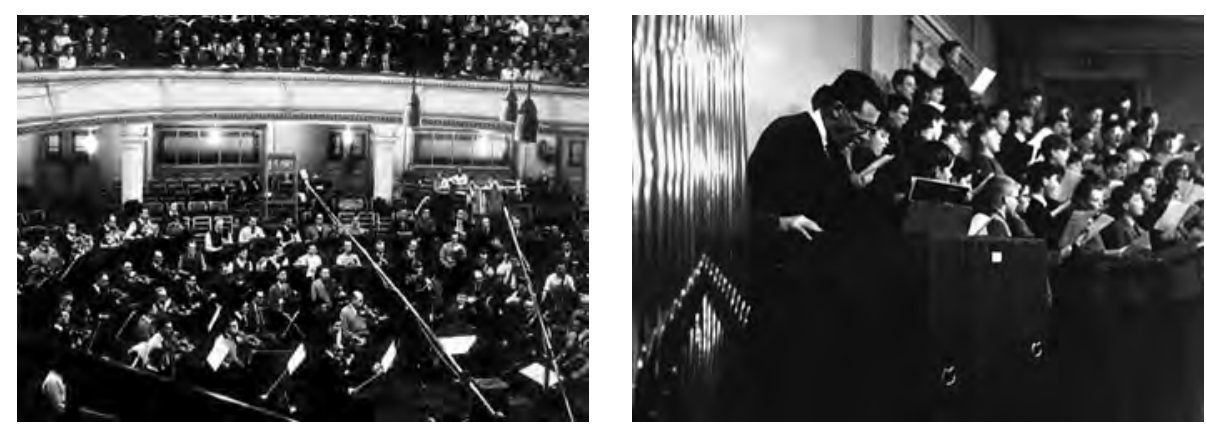

Imagen 6.

Tres imágenes de

las sesiones de grabación del War Requiem en enero de 1963 en el Kingsway Hall.

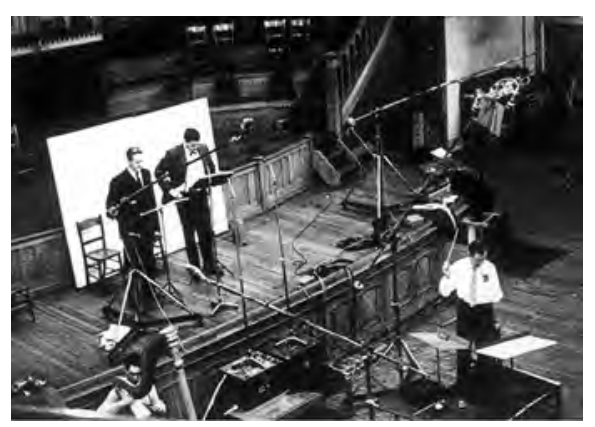

dres; fue demolida en 1998 y convertida en 2000 en un lujoso hotel de cuatro estrellas que tan sólo conserva el nombre ${ }^{17}$.

Para la grabación Culshaw había diseñado un sistema de colocación que permitía individualizar perfectamente los tres conjuntos sonoros de la obra: la soprano con la orquesta y coro, el coro de niños con el órgano y los dos solistas masculinos con el conjunto instrumental. Por un lado, situó a la orquesta en el centro del patio de butacas y al coro con la solista femenina en el graderío superior opuesto al escenario; el coro de niños se colocó arriba del escenario en las graderías del órgano; y los dos solistas ocuparon el centro del escenario con el conjunto instrumental a sus pies (imagen 6$)^{18}$.

17. Se trata de un lugar muy emblemático para John Culshaw no solo porque en él produjo muchas de sus grabaciones, sino también porque allí se celebró su funeral el 24 de junio de 1980 con la participación de algunos de los artistas con los que había trabajado como el pianista Clifford Curzon, el trompista Alan Civil, los directores de orquesta Georg Solti y Lorin Maazel o la soprano Leontyne Price junto a colegas de la BBC como Humphrey Burton. Véase: http://en.wikipedia.org/wiki/Kingsway_Hall.

18. Culshaw cuenta alguna anécdota curiosa relacionada con esta colocación, como la queja que le formuló la soprano rusa Galina Vishnevskaya, que no hablaba inglés y consideró su colocación con el coro una grave discriminación soviética por parte de occidente. Cfr. Culshaw: Putting the Record Straight, op. cit., pp. 310-312. 


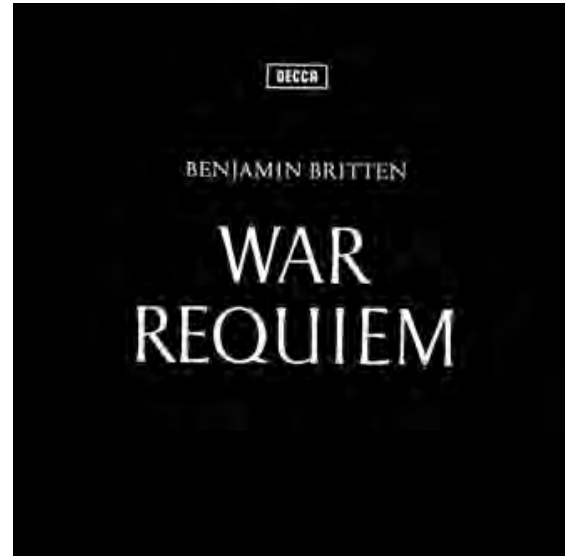

Imagen 7. Portada de la primera edición en LP que lanzó Decca del War Requiem de Britten.

Podría ahondarse con más profundidad en las particularidades de esta grabación, como en su fenomenal recepción que resultó enormemente rentable, o en curiosidades, como su portada de negro riguroso y tan sólo con el nombre del sello británico, el del compositor y el título de la obra (imagen 7). Sin embargo, mucho más importante resultó la influencia que marcó el diseño de Culshaw en las posteriores interpretaciones de la obra.

La primera interpretación del War Requiem después de la grabación de Decca tuvo lugar durante los populares Proms londinenses en el Royal Albert Hall, el 4 de agosto de 1964, como conmemoración de los 50 años del comienzo de la Primera Guerra Mundial. En la retransmisión televisiva del concierto de la BBC puede verse esa misma colocación con la soprano británica Heather Harper en el centro del coro o con Britten, que renunció a dirigir todo el conjunto, al frente del grupo instrumental con los dos solistas masculinos en un apartado a la derecha del director (imagen 8).
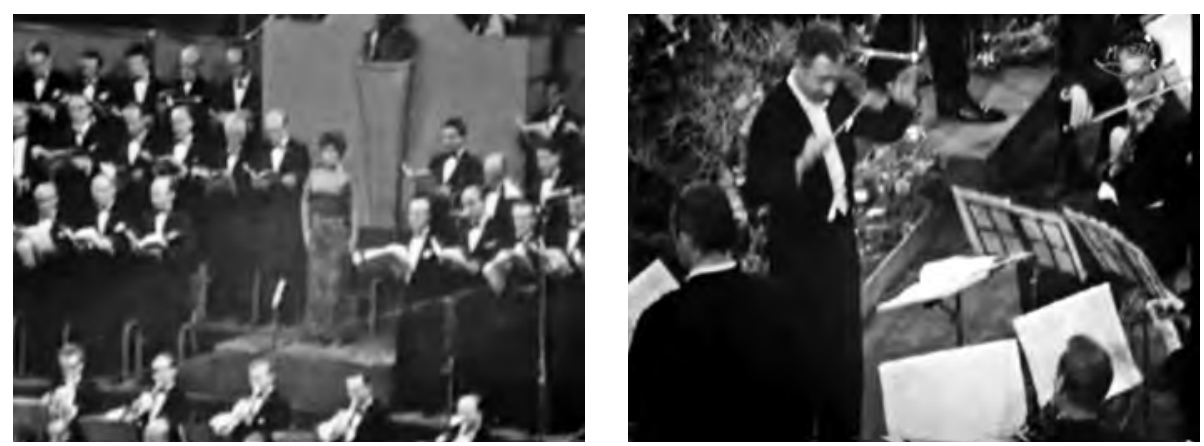

Imagen 8. Dos imágenes de la interpretación del War Requiem en los Proms de 1964. 
Culshaw dejó en 1967 su puesto como principal productor de Decca para suceder a Humphrey Burton al frente de la programación musical de la BBC. Ese cambio supuso para él una oportunidad para ampliar sus ideas artísticas al universo visual. De hecho, si había tratado de paliar de forma artística la ausencia de imagen en la grabación sonora, ahora trataría de integrar esa imagen al servicio de la música de forma también creativa pero también respetuosa. Desgraciadamente, Culshaw no vivió para incluir en su autobiografía sus experiencias como productor fílmico, pero publicó un ensayo en la revista Gramophone en 1970 donde muestra con claridad sus pretensiones hacia el medio visual ${ }^{19}$. Sus mayores preocupaciones se centran en diseñar una programación de registros visuales susceptibles de formar parte del incipiente pero potencial mercado del video doméstico. El productor británico aboga por un video con una calidad sonora similar al disco de alta fidelidad y ajustado al reducido tamaño que por entonces tenían los televisores domésticos; considera crucial conseguir que lo filmado tenga el interés visual suficiente para que sea atractivo reproducirlo en más de una ocasión, tal como sucede con los discos. Por esa razón, rechaza la filmación de conciertos sinfónicos ("¿realmente quiere usted ver a ese oboísta con una espinilla en su nariz cada vez que escucha cierta frase de una sinfonía de Beethoven?"). Se decanta por la ópera y el ballet pero considera necesario encontrar una "gramática" que haga deseable varias visualizaciones de un mismo video; pone como ejemplo de ello en el ámbito escénico la régie de Wieland Wagner del Parsifal de Wagner en Bayreuth que renuncia a todo lo que no es esencial para lograr una sorprendente pero calculada simplicidad que, unida a la impresionante continuidad de imágenes y movimientos en relación con la música, imposibles de memorizar, lo que hace que cada nueva visualización suponga una nueva experiencia. Avisa de los peligros de limitarse a encontrar paralelismos entre la historia de los registros fonográficos y el video y destaca el interés que pueden tener obras escénicas especialmente concebidas para su filmación, poniendo como ejemplo Pas de Deux de Norman McLaren o Limbo de Alwin Nikolai; Culshaw no cita a Britten, pero en el trasfondo de su argumentación se encuentra la ópera Owen Wingrave que el compositor británico había escrito por encargo de la BBC para su filmación televisiva, y cuya realización dirigió dos meses más tarde de la publicación de este artículo.

No obstante, para comprender cómo Culshaw y Britten Ilegaron a Owen Wingrave es crucial explicar brevemente el paso previo que supuso la filmación de Peter Grimes en febrero de $1969^{20}$. Uno de los primeros proyectos que Culshaw desarrolló desde su nuevo puesto como director musical de la BBC fue promover la producción televisiva de óperas de Britten; el compositor británico

19. John Culshaw: "The Outlook for Video Music" en Gramophone (September, 1970), pp. 399-400.

20. Britten: Peter Grimes. DVD. Decca 9743261DH @2008. 
había trabajado con Basil Coleman pero no quería rodar en un plató de televisión sino en su recientemente renovado auditorio de Snape Maltings en Suffolk, sede de su Festival de Aldeburgh. Coleman renunció a dirigir filmaciones en ese lugar debido a lo complicado que era adaptarlo al medio televisivo y ello obligó a Culshaw a diseñar todo un nuevo sistema productivo que él mismo coordinaría; dividió la labor de Coleman en dos: un "director de artistas" encargado de los gestos y movimientos de la puesta en escena teatral de los cantantes y el coro y un "director de cámaras" cuyo cometido será la efectiva creación en la pantalla televisiva de todo el trabajo realizado por el director de artistas. Para el primer puesto eligió a la veterana Joan Cross, la cantante que inspiró y estrenó el papel de Ellen Orford de Peter Grimes, y para el segundo a un joven Brian Large, que con el tiempo se convirtió en el principal director de filmaciones de música clásica editadas en DVD y, especialmente, del popular Concierto de Año Nuevo. Culshaw se reservó para sí mismo la máxima responsabilidad y capacidad decisoria del proyecto como productor en el caso de una eventual disconformidad entre el director artístico y el fílmico ${ }^{21}$.

Aunque Peter Grimes sentó las bases, el proyecto filmográfico más ambicioso de Culshaw fue la producción del estreno de Owen Wingrave, la penúltima ópera de Britten escrita para la televisión, filmada en noviembre de 1970 y estrenada por televisión en mayo de $1971^{22}$. La obra está basada en un relato homónimo de Henry James y cuenta con el libreto de Myfanwy Piper; su trama está protagonizada por Owen, un muchacho de la honorable familia Wingrave, vinculada al mundo militar desde hace varias generaciones; Owen no quiere formar parte de ese mundo militarista y el conflicto con su familia es el corazón de la historia que le llevará a morir prematuramente. Hay varios momentos de la obra donde el lenguaje cinematográfico funciona a la perfección con el musical; por ejemplo, en el inicio del segundo acto escuchamos a Peter Pears cantar una balada donde narra la trágica historia de un antepasado de los Wingrave y la evocadora visualización de esa narración se conecta perfectamente con la acción de la ópera a través de un cuadro que visualizan Owen y su profesor. La ópera se estrenó escénicamente en 1973 en el Covent Garden con poco éxito; no hay duda que se trata de un título profundamente vinculado al medio televisivo como lo demuestra el remake de 2001 dirigido por Margaret Williams y musicalmente por Kent Nagano para Channel 4 (véase la imagen 9) ${ }^{23}$.

El 9 de mayo de 1971, justamente una semana antes del estreno televisivo de Owen Wingrave, se emitió en BBC Two un breve documental acerca de la

21. Jennifer Barnes: Television Opera. The Fall of Opera Commissioned for Television. Woodbridge: The Boydell Press, 2003, pp. 56-59.

22. Ib., pp. 59-80. Véase además Britten: Owen Wingrave. DVD. Decca 0743330DH (c)2009.

23. Britten: Owen Wingrave. DVD. Arthaus Musik 100373 @2010. 

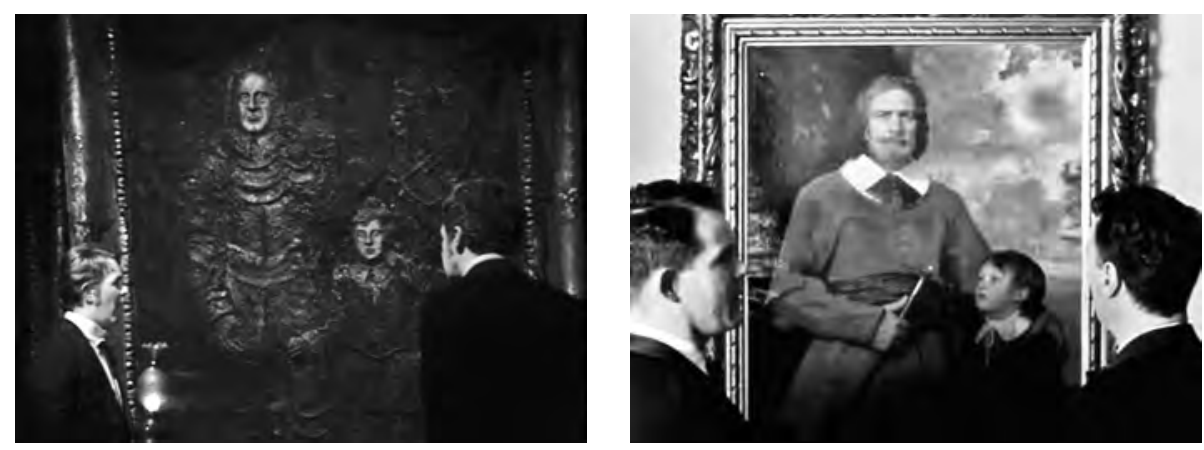

Imagen 9. Inicio de la escena primera del segundo acto de Owen Wingrave en la producción de la BBC de 1970 y Channel 4 de 2001.

nueva ópera de Britten ${ }^{24}$. En él se muestra cómo se filmó en la antigua fábrica de malta de cebada que Britten convirtió en el famoso auditorio del Festival de Aldeburgh junto a varias intervenciones de los cantantes, el escenógrafo, la libretista, el director de cámaras y termina con la única entrevista conocida entre John Culshaw y Benjamin Britten. El compositor reconoce al productor que buscó una historia que resultase adecuada para el medio televisivo y, aunque había leído hace tiempo el cuento de Henry James, nunca pensó en él para una ópera hasta conocer las posibilidades de la ópera televisiva: "una ópera que muestra individuos que reaccionan entre sí y donde los eventos son de tipo personal y privado en vez de grandes y públicos". No hay duda de que el compositor adaptó a un terreno privado la habitual confrontación pública del individuo frente a la comunidad, presente en otras óperas como Peter Grimes, en este caso como confrontación doméstica de un individuo frente a su tradición familiar. Y en ese cambio de concepción fue determinante la influencia del entorno televisivo y especialmente a través de las ideas de John Culshaw.

24. Ese breve documental puede verse en la edición de Decca en DVD de Owen Wingrave arriba citada. 